\title{
Capacidade antioxidante e composição química da casca de maracujá (Passiflora edulis)
}

\author{
Antioxidant capacity and chemical composition of passion fruit peel (Passiflora edulis)
}

\author{
Cinthia Baú Betim Cazarin I Juliana Kelly da Silva ${ }^{\mathrm{I}}$ Talita Cristina Colomeu ${ }^{\mathrm{II}}$ \\ Ricardo de Lima Zollner ${ }^{I I}$ Mário Roberto Maróstica Junior ${ }^{{ }^{*}}$
}

RESUMO

O objetivo do estudo foi avaliar a composição centesimal da farinha obtida da casca do maracujá e sua atividade antioxidante in vitro, buscando viabilizar suas potencialidades para incorporação em produtos alimentares. Os frutos foram higienizados, as cascas foram separadas da polpa, secas em estufa com circulação de ar e moídas para obtenção de uma farinha. Foi determinada a composição centesimal e os polifenóis presentes na casca foram extraídos por três metodologias, tendo sido quantificados o teor de fenóis totais e a atividade antioxidante por três métodos distintos (sequestro do radical 2,2-difenil-1-picrilhidrazil - DPPH, capacidade antioxidante de redução do ferro - FRAP e capacidade de absorção do radical oxigênio - ORAC). Os resultados mostram que a farinha apresenta elevado teor de fibras $(65,22 \pm 0,27 \%)$, das quais $74 \%$ são fibras insolúveis. Embora os resultados do teor de polifenóis indiquem que possivelmente há um predomínio de compostos com características hidrofilicas na casca, visto que a água foi o solvente que apresentou maior rendimento na extração dos fenóis totais, a avaliação da atividade antioxidante dos extratos mostra que o poder antioxidante dos compostos lipofílicos presentes no extrato metanólico/acetona foram superiores ao dos compostos presentes no extrato aquoso e etanólico. Os resultados obtidos no presente estudo demonstram que a casca do maracujá poderia ser utilizada como fonte de fibras e antioxidantes. No entanto, sua incorporação em formulações alimentares deve atentar as suas características físicas, químicas e sensoriais, para garantir seu melhor aproveitamento e aceitação entre os consumidores.

Palavras-chave: Passiflora edulis, casca do maracujá, fibra dietética, compostos fenólicos, atividade antioxidante.

\section{ABSTRACT}

The aim of the study was to evaluate the chemical composition of flour obtained from the peel of passion fruit and their antioxidant activity in vitro. The fruits were cleaned, the peels were separated from pulp, dried in an oven with circulating air and ground to obtain the flour. The centesimal composition was determined and the polyphenols present in the peel were extracted by three methodologies. Total phenolic content and antioxidant activity were determined using three different methods (scavenging of 2,2-diphenyl-1-picrylhydrazyl - DPPH free radical, Ferric Reducing Antioxidant Power - FRAP e Oxigen Radical Absorbance Capacity - ORAC). The results show that the flour has high fiber content (65.22 $\pm 0.27 \%$ ) and $74 \%$ of which correspond to insoluble fraction. Although the results of total polyphenol indicate that there is a predominance of compounds with hydrophilic characteristics in the peel, the evaluation of the antioxidant activity of the extracts showed that the antioxidant power of lipophilic compounds present in the methanol / acetone extract was superior to the compounds present in the aqueous and ethanol extracts. The results of this study demonstrate that the passion fruit peel could be used as a source of fiber and antioxidants, however, its incorporation into food formulations must address their physical, chemical and sensory, to ensure their best use and acceptance among consumers.

Key words: Passiflora edulis, passion fruit peel, dietary fiber, phenolic compounds, antioxidant activity.

\section{INTRODUÇÃO}

Maracujá é um nome popular dado a várias espécies do gênero Passiflora, do qual há 500 espécies distribuídas por regiões de clima tropical e subtropical do globo, sendo o Brasil seu maior produtor com mais de 79 espécies (ZERAIK et al., 2010). Sua produção anual equivale a 923 mil toneladas, com destaque

'Departamento de Alimentos e Nutrição, Faculdade de Engenharia de Alimentos, Universidade Estadual de Campinas (UNICAMP), Rua Monteiro Lobato, 80, Cidade Universitária Zeferino Vaz, 13083-862, Campinas, SP, Brasil. E mail: mario@fea.unicamp.br. *Autor para correspondência.

IIDepartamento de Clínica Médica, Faculdade de Ciências Médicas, UNICAMP, Campinas, SP, Brasil. 
para as regiões produtoras nordeste e sudeste (IBGE, 2012). O maracujá Passiflora edulis, conhecido como maracujá azedo ou amarelo, é o mais produzido e comercializado (ZERAIK et al., 2010), representando 95\% dos pomares (MELETTI \& BRUKNER, 2001). Seu cultivo está basicamente voltado para a indústria de sucos e polpas, em especial devido ao seu sabor mais ácido e maior rendimento (ZERAIK et al., 2010); além de apresentar em sua composição elevado teor de carotenoides $\left(15,36\right.$ a $\left.27,14 \mathrm{mg} \mathrm{g}^{-1}\right)$ (SILVA \& MERCADANTE, 2002).

Casca e semente do maracujá, subprodutos da indústria de alimentos, podem apresentar características de interesse tecnológico e biológico (MARTINEZ et al., 2012), sendo que mais de $75 \%$ deste resíduo poderia ser transformado em ingrediente com propriedades bioativas para promoção de saúde (ARVANITOYANNIS, 2008).

A casca do maracujá é composta pelo flavedo, que corresponde à camada externa de coloração verde a amarela, rica em fibras insolúveis e o albedo, que corresponde à camada interna branca, que é rica em fibra solúvel, em especial a pectina, com pequenas quantidades de mucilagens (JANEBRO et al., 2008). Além disso, a casca do maracujá $\boldsymbol{P}$. edulis apresenta em sua composição compostos fenólicos com atividade antioxidante e anti-inflamatória, como é o caso da isoorientina $\left(1,230 \pm 0,008 \mathrm{mg} \mathrm{g}^{-1}\right.$ casca seca) (ZERAIK et al., 2012).

Assim, o presente estudo teve como objetivo avaliar a composição centesimal e a atividade antioxidante in vitro da farinha obtida da casca do maracujá, um subproduto da indústria de alimentos.

\section{MATERIAL E MÉTODOS}

Foram utilizadas amostras de maracujá (Passiflora edulis), colhidas em junho de 2010, provenientes de um produtor de cultivo orgânico em Torre de Pedra/SP. Os frutos foram lavados, a polpa foi separada da casca, que foi seca em estufa com circulação de ar $50^{\circ} \mathrm{C}$ (Marconi, Piracicaba/SP - Brasil), até obtenção de teor de umidade igual ou inferior a $10 \%$. As cascas foram moídas em moinho de martelos (20 mesh) até obtenção da farinha (FCM), que foi estocada em frasco âmbar em temperatura ambiente até o momento das análises $\left(24^{\circ} \mathrm{C}\right)$.

$\mathrm{A}$ atividade de água $\left(\mathrm{a}_{\mathrm{w}}\right)$ da farinha foi avaliada em equipamento AquaLab (Pullman, WA, USA) a $24,7^{\circ} \mathrm{C}$ e a composição centesimal foi determinada quanto ao teor de umidade, cinzas e proteínas (AOAC, 2006), lipídeos (BLIGH \& DYER, 1959). O conteúdo de fibra dietética total e fração insolúvel foram determinados por método gravimétrico (PROSKY et al., 1988) e a fração solúvel calculada a partir da diferença entre fibra dietética total e fração insolúvel, resultados descritos em estudo prévio (DA SILVA, et al., 2014).

O teor de polifenóis e a avaliação da atividade antioxidante da casca foram determinados em três extratos distintos: aquoso, metanólico + acetona e etanólico. Para o preparo do extrato aquoso, foi pesado $1 \mathrm{~g}$ da $\mathrm{FCM}$ e adicionados $25 \mathrm{~mL}$ de água fervente. Após 35 minutos, o extrato foi filtrado a vácuo e estocado sob refrigeração $\left(2\right.$ to $\left.8^{\circ} \mathrm{C}\right)$, protegido da luz até momento da análise.

O preparo do extrato aquoso baseou-se na metodologia descrita por da Silva et al. (2014), o preparo do extrato metanólico + acetona na metodologia descrita por Larrauri, Ruperez and SauraCalixto (LARRAURI et al., 1997) e o extrato etanólico foi preparado baseado na metodologia descrita por (SPAGOLLA et al., 2009).

O conteúdo total de fenólicos foi determinado de acordo com a metodologia de FolinCiocalteu (SWAIN \& HILLIS, 1959). A presença dos compostos fenólicos vitexina, isovitexina, iso-orientina e apigenina foi investigada por meio de análise cromatográfica com um sistema de cromatografia líquida acoplada a um detector de fotodiodo (Agilent Technologies 1200 series - Englewood, CO, USA). As condições cromatográficas utilizadas estão descritas em um estudo prévio, realizado com as folhas de $\boldsymbol{P}$. edulis (DA SILVA et al., 2013).

A capacidade antioxidante dos extratos foi testada pelas técnicas de DPPH (BRACA et al., 2001), FRAP (BENZIE \& STRAIN, 1999) e ORAC Hidrofílico (PRIOR et al., 2003).

Para as análises estatísticas, foi utilizado o software GraphPad Prism 5.0 (GraphPad Software, Inc. La Jolla, CA, USA) e todos os resultados foram expressos em média \pm erro padrão da média (SEM). As determinações foram efetuadas em triplicata e os dados submetidos à análise de variância ANOVA e as médias comparadas pelo teste de Tukey ao nível de significância de 5\%.

\section{RESULTADOS E DISCUSSÃO}

A farinha obtida da moagem da casca do maracujá (P. edulis) apresentou baixo teor de umidade e de $\mathrm{a}_{\mathrm{w}}$ (Tabela 1), a qual promove proteção à farinha contra alterações microbiológicas, visto que o crescimento bacteriano se dá em $\mathrm{a}_{\mathrm{w}}$ entre 0,6 e 0,9 (LABUZA \& ALTUNAKAR, 2008).

O teor de fibra alimentar total (FDT) (Tabela 1) encontrado na FCM foi 1,25 vezes 
Tabela 1 - Composição centesimal da farinha da casca do maracujá (g $100 \mathrm{~g}^{-1}$, base seca).

\begin{tabular}{ll}
\hline Componente & Média \pm DP \\
\hline Atividade de água $\left(\mathrm{a}_{\mathrm{w}}\right)$ & $0,43 \pm 0,02$ \\
Umidade & $9,48 \pm 0,26$ \\
Cinzas & $6,88 \pm 0,02$ \\
Proteínas & $3,94 \pm 0,18$ \\
Lipídeos $^{£}$ & $0,31 \pm 0,01$ \\
Fibra dietética total $^{£}$ & $65,22 \pm 0,27$ \\
Fibra insolúvel $^{£}$ & $48,12 \pm 1,10$ \\
Fibra solúvel $^{£}$ & $17,11 \pm 1,36$ \\
Carboidratos* $^{*}$ & 79,39 \\
\hline
\end{tabular}

E Valor obtido por meio da diferença entre a soma dos macronutrientes subtraído de $100 \%$.

menor que a anteriormente descrita, no entanto, a relação fibra insolúvel e solúvel, encontrada na FCM se manteve similar (YAPO \& KOFFI, 2008), o que se encontra de acordo com o esperado para a obtenção de efeitos fisiológicos benéficos (70:30) (SCHNEEMAN, 1987). O conteúdo de FDT supera os resultados encontrados em outros subprodutos da indústria de alimentos, como cascas de manga $(51,2 \pm 1,1 \%)$ (AJILA et al., 2010), goiaba $(48,55 \pm 2,16 \%)$ (JIMENEZ-ESCRIG et al., 2001), laranja (57\%) (CHAU \& HUANG, 2003), banana $(50,3 \pm 0,2 \%)$ (WACHIRASIRI et al., 2009). Em geral, as cascas utilizadas como fonte de fibras apresentam em sua composição maior concentração de fibras insolúveis, que garantem aos vegetais, dentre outras funções, a manutenção de sua morfologia. O consumo humano das fibras dietéticas promove diversos efeitos fisiológicos benéficos, dentre os quais podemos citar formação de ácidos graxos de cadeia curta, os quais apresentam atividade anti-carcinogênica (TANG et al., 2011); promoção do aumento do volume e da viscosidade fecal e diminuição do tempo de contato de substâncias potencialmente carcinogênicas com a mucosa (VUKSAN et al., 2008); além de aumentar o status antioxidante (GOÑI \& SERRANO, 2005).

Estudos têm demonstrado que o consumo da casca do maracujá pode ajudar no tratamento coadjuvante do controle glicêmico, com diminuição significativa na glicemia de jejum, hemoglobina glicada, índice HOMA IR e aumento no índice HOMA (QUEIROZ et al., 2012); assim como no controle lipêmico, promovendo redução do colesterol total e fração LDL (RAMOS et al., 2007). Além disso, estudo com modelo experimental demonstrou efeito anti-inflamatório, com diminuição do volume do edema, liberação de mieloperoxidase, infiltração de neutrófilos e da expressão de TNF- $\alpha$ e iNOS (SILVA et al., 2011).

O conteúdo de polifenóis totais na FCM (Tabela 2) foi semelhante ao encontrado em outras cascas de frutas (tangor, limão, kumquat, calamondin, pamplemousses e bergamota de $1882 \pm 65$ a $7667 \pm 57 \mu \mathrm{g} \mathrm{g}^{-1}$ ) (RAMFUL et al., 2010). Em geral, o teor de polifenóis neste tipo de subproduto mostrase superior ao encontrado na porção comestível ou polpa dos frutos (TEHRANIFAR et al., 2011), possivelmente porque os polifenóis são metabólitos secundários dos vegetais, os quais estão geralmente envolvidos na defesa contra a radiação ultravioleta ou a agressão por agentes patogênicos. Aos compostos fenólicos encontrados na casca do maracujá, têm sido atribuídos efeitos anti-inflamatório (ZERAIK et al., 2011; ZERAIK et al., 2012) e anti-hipertensivo (LEWIS etal., 2013). Os compostos fenólicos vitexina, isovitexina, isoorientina e apigenina, previamente encontrados na casca do maracujá de distintas espécies (ZERAIK et al., 2012; SIMIRGIOTIS

Tabela 2 - Avaliação da atividade antioxidante e do teor de compostos fenólicos totais da farinha obtida da casca do maracujá Passiflora edulis.

\begin{tabular}{llll}
\hline Componente & Aquoso & Metanólico/Acetona & Etanólico \\
\hline Fenóis totais* & $2,53 \pm 0,03^{\mathrm{a}^{\mathrm{e}}}$ & $2,30 \pm 0,01^{\mathrm{b}}$ & $2,06 \pm 0,08^{\mathrm{c}}$ \\
DPPH (\%) & $46,35 \pm 0,85^{\mathrm{a}}$ & $32,5 \pm 2,52^{\mathrm{b}}$ & $29,6 \pm 0,66^{\mathrm{c}}$ \\
FRAP** & $36,56 \pm 0,99^{\mathrm{b}}$ & $38,65 \pm 1,55^{\mathrm{a}}$ & $34,95 \pm 2,02^{\mathrm{b}}$ \\
ORAC Hidrofílico** $^{*}$ & $68,58 \pm 0,06^{\mathrm{a}}$ & $63,48 \pm 0,03^{\mathrm{a}}$ \\
\hline
\end{tabular}

*(mg equivalentes de ácido gálico EAG g-1 de amostra); **( $\mu$ mol Trolox equivalentes TE g-1 de amostra).

${ }^{£}$ Resultados previamente apresentados em DA SILVA ET AL. (2014). Letras diferentes na mesma linha representam diferença estatística $(\mathrm{P}<0,05)$. 
et al., 2013), não foram identificados na análise cromatográfica dos extratos utilizados no presente. Existem vários fatores que podem ter contribuído para a não identificação deles nos extratos, dentre elas, podemos citar a baixa concentração de casca na preparação dos extratos e ineficiência dos solventes na extração destes compostos.

A avaliação da atividade antioxidante (Tabela 2), avaliada pelo método DPPH, mostrou maior atividade antioxidante no extrato aquoso em comparação com os extratos metanólico / acetona e etanólico. Quando avaliado pela técnica FRAP, o extrato metanólico / acetona apresentou maior atividade antioxidante que os extratos etanólico e aquoso, além disso, a capacidade antioxidante de redução do ferro da FCM foi superior à encontrada em algumas frutas colombianas (CONTRERAS-CALDERÓN et al., 2011). Os resultados de ORAC mostraram diferença estatística significativa $(\mathrm{P}<0,0001)$ entre os extratos (metanólico / acetona $>$ etanólico $>$ aquoso). Em suma, a água foi o melhor solvente na extração dos polifenóis, no entanto, apresentou menor atividade antioxidante, comparado ao extrato metanólico / acetona nos ensaios FRAP e ORAC. A utilização de solventes orgânicos na extração de polifenóis vem sendo utilizado há décadas, porém há uma preocupação com relação aos efeitos tóxicos e viabilidade de aplicação destes extratos na indústria de alimentos e farmacêutica. Dessa maneira, os estudos vêm ao longo dos anos tentando identificar solventes (diferentes polaridades) que não sejam nocivos e que assegurem um melhor rendimento na extração dos polifenóis (AGARWAL et al., 2012). A escolha do solvente utilizado na extração influenciará diretamente o tipo de composto extraído, devido à característica química dos polifenóis.

\section{CONCLUSÃO}

Os resultados obtidos no presente estudo demonstram que a casca do maracujá, subproduto da indústria de sucos e polpas, poderia ser utilizada como fonte de fibras. Sua incorporação na formulação de alimentos deve atentar as suas características físicas, químicas e sensoriais, para garantir seu melhor aproveitamento e aceitação entre os consumidores.

\section{AGRADECIMENTOS}

À Fundação de Amparo a Pesquisa do Estado de São Paulo - FAPESP (Processo n.2010/10131-7, 2010/16752-3 e 2012/24262-1), Coordenação de Aperfeiçoamento de Pessoal de Nível Superior (CAPES) e Conselho Nacional de Desenvolvimento Científico e Tecnológico (CNPq), pela concessão de bolsas de estudos e financiamento do projeto. Aos produtores de maracujá orgânico da cidade de Torre de Pedra/SP, Saulo Aidar e Vanderlei Agostini, pela doação dos frutos.

\section{REFERENCIAS}

AGARWAL, M. et al. Extraction of polyphenol, flavonoid from Emblica officinalis, citrus limon, cucumis sativus and evaluation of their antioxidant activity. Oriental Journal of Chemistry, v.28, n.2, p.993-998, 2012. Disponível em: <www.orientjchem.org>. Acesso em: 14 nov. 2013.

AJILA, C.M. et al. Mango peel powder: A potential source of antioxidant and dietary fiber in macaroni preparations. Innovative Food Science \& Emerging Technologies, v.11, n.1, p.219-224,2010. Disponível em: <http://dx.doi.org/10.1016/j. ifset.2009.10.004>. Acesso em: 14 nov. 2013.

AOAC. Official Methods of Analysis of AOAC International. 18.ed. Gaithersburg, 2006.

ARVANITOYANNIS, I.S. 1 - Potential and representatives for application of environmental management system (EMS) to food industries. In: IOANNIS, S.A. et al. (Ed.). Waste management for the food industries. Amsterdam: Academic, 2008. p.3-38. ISBN 978-0-12-373654-3.

BENZIE, I.F.; STRAIN, J.J. Ferric reducing/antioxidant power assay: direct measure of total antioxidant activity of biological fluids and modified version for simultaneous measurement of total antioxidant power and ascorbic acid concentration. Methods in Enzymology, v.299, p.15-27,1999

BLIGH, E.G.; DYER, W.J. A rapid method of total lipid extraction and purification. Canadian Journal of Biochemistry and Physiology, v.37, n.8, p.911-7, 1959. Disponível em: <http:// www.ncbi.nlm.nih.gov/pubmed/13671378>. Acesso em: 16 ago. 2012 .

BRACA, A. et al. Antioxidant Principles from Bauhinia tarapotensis. Journal of Natural Products, v.64, n.7, p.892-895, 2001. Disponível em: <http://dx.doi.org/10.1021/np0100845>. Acesso em: 16 ago. 2012.

CHAU, C.-F.; HUANG, Y.-L. Comparison of the Chemical Composition and Physicochemical Properties of Different Fibers Prepared from the Peel of Citrus sinensis L. Cv. 'Liucheng'. Journal of Agricultural and Food Chemistry, v.51, n.9, p.26152618, 2003. Disponível em: <http://dx.doi.org/10.1021/jf025919b>. Acesso em: 17 ago. 2012.

CONTRERAS-CALDERÓN, J. et al. Antioxidant capacity, phenolic content and vitamin $\mathrm{C}$ in pulp, peel and seed from 24 exotic fruits from Colombia. Food Research International, v.44, n.7, p.2047-2053, 2011. Disponível em: <http://dx.doi. org/10.1016/j.foodres.2010.11.003>. Acesso em: 14 nov. 2013.

DA SILVA, J.K. et al. Antioxidant activity of aqueous extract of passion fruit (Passiflora edulis) leaves: in vitro and in vivo study. Food Research International, v.53, n.2, p.882-890, 2013. Disponível em: <http://dx.doi.org/10.1016/j.foodres.2012.12.043>. Acesso em: 14 nov. 2013.

DA SILVA, J. K. et al. "Passion fruit (Passiflora edulis) peel increases colonic production of short-chain fatty acids in Wistar rats." LWT - Food Science and Technology (In press), 2014. 
Disponível em: <http://dx.doi.org/10.1016/j.1wt.2014.05.030>, Acesso em: 20 jun. 2014.

GOÑI, I.; SERRANO, J. The intake of dietary fiber from grape seeds modifies the antioxidant status in rat cecum. Journal of the Science of Food and Agriculture, v.85, n.11, p.1877-1881, 2005. Disponível em: <http://dx.doi.org/10.1002/jsfa.2213>. Acesso: 14 nov. 2013.

IBGE, I.B.D.G.E.E. (INSTITUTO BRASILEIRO DE GEOGRAFIA E ESTATÍSTICA). Anuário Estatístico do Brasil. Rio de Janeiro, 2012. $458 \mathrm{pag}$.

JANEBRO, D. I. et al. Efeito da farinha da casca do maracujáamarelo (Passiflora edulis f. flavicarpa Deg.) nos níveis glicêmicos e lipídicos de pacientes diabéticos tipo 2. Revista Brasileira de Farmacognosia, v.18, p.9, 2008.

JIMENEZ-ESCRIG, A. et al. Guava fruit (Psidium guajava L.) as a new source of antioxidant dietary fiber. Journal of Agricultural and Food Chemistry, v.49, n.11, p.5489-5493, 2001.

LABUZA, T.P.; ALTUNAKAR, L. Water activity prediction and moisture sorption isotherms. In: BARBOSA-CÁNOVAS, G.V. et al (Ed). Water activity in foods: Fundamentals and Applications. Local: Oxford. Blackwell Publishing, 2008. p.109-154. ISBN 9780470376454

LARRAURI, J.A. et al. Effect of drying temperature on the stability of polyphenols and antioxidant activity of red grape pomace peels. Journal of Agricultural and Food Chemistry, v.45, n.4, p.1390-1393, 1997.

LEWIS, B.J. et al. Antihypertensive effect of passion fruit peel extract and its major bioactive components following acute supplementation in spontaneously hypertensive rats. Journal of Nutritional Biochemistry, v.24, n.7, p.1359-1366, 2013.

MARTINEZ, R. et al. Chemical, technological and in vitro antioxidant properties of mango, guava, pineapple and passion fruit dietary fibre concentrate. Food Chemistry, v.135, n.3, p.1520-1526, 2012.

MELETTI, L.M.M.; BRUKNER, C.H. Melhoramento genético. In: BRUKNER, C.H.; PICANÇO, M.C. (Ed.). Maracujá tecnologia de produção, pós-colheita, agroindústria e mercado. Porto Alegre: Cinco Continentes, 2001. p.345-385.

PRIOR, R.L. et al. Assays for hydrophilic and lipophilic antioxidant capacity (oxygen radical absorbance capacity (ORAC(FL))) of plasma and other biological and food samples. Journal of Agricultural and Food Chemistry, v.51, n.11, p.3273-3279, 2003.

PROSKY, L. et al. Determination of insoluble, soluble, and total dietary fiber in foods and food products: interlaboratory study. Journal of the Association of Official Analytical Chemists, v.71, n.5, p.1017-1023,1988. Disponível em: $<$ http://www.ncbi.nlm.nih.gov/pubmed/2853153>. Acesso em: 14 nov. 2013.

QUEIROZ, M.S.R. et al. Effect of the yellow passion fruit peel flour (Passiflora edulis f. flavicarpa deg.) in insulin sensitivity in type 2 diabetes mellitus patients. Nutrition Journal, v.11, p.89, 2012. Disponível em: $<\mathrm{http}: / /$ www.nutritionj.com/content/11/1/89 $>$. Acesso em: 14 nov. 2013.
RAMFUL, D. et al. Bioactive phenolics and antioxidant propensity of flavedo extracts of Mauritian citrus fruits: Potential prophylactic ingredients for functional foods application. Toxicology, v.278, n.1, p. 75-87, 2010.

RAMOS, A.T. et al. Uso de Passiflora edulis f. flavicarpa na redução do colesterol. Revista Brasileira de Farmacognosia, v.17, p.592-597, 2007.

SCHNEEMAN, B.O. Soluble vs insoluble fiber-different physiologicalresponses. Food Technology, v.41, n.2, p.81-82, 1987.

SILVA, D.C. et al. Pectin from Passiflora edulis shows anti-inflammatory action as well as hypoglycemic and hypotriglyceridemic properties in diabetic rats. Journal of Medicinal Food, v.14, n.10, p.1118-1126, 2011.

SILVA, S.R.D.; MERCADANTE, A.Z. Composição de carotenóides de maracujá-amarelo (Passiflora edulis flavicarpa) in natura. Food Science and Technology, v.22, p.254-258, 2002.

SIMIRGIOTIS, M.J. et al. The Passiflora tripartita (Banana Passion) fruit: a source of bioactive flavonoid c-glycosides isolated by HSCCC and characterized by HPLC-DAD-ESI/MS/MS. Molecules, v.18, n.2, p.1672-1692, 2013.

SPAGOLLA, L.C. et al. Extração alcoólica de fenólicos e flavonóides totais de mirtilo "Rabbiteye" (Vaccinium ashei) e sua atividade antioxidante. Journal of Basic and Applied Pharmaceutical Sciences, v.30, n.2, p.187-191, 2009.

SWAIN, T.; HILLIS, W.E. The phenolic constituents of Prunus domestica. I.-The quantitative analysis of phenolic constituents. Journal of the Science of Food and Agriculture, v.10, n.1, p.63-68, 1959. Disponível em: <http:// dx.doi.org/10.1002/jsfa.2740100110>. Acesso em: 14 nov. 2013.

TANG, Y. et al. The role of short-chain fatty acids in orchestrating two types of programmed cell death in colon cancer. Autophagy, v.7, n.2, p.235-237, 2011.

TEHRANIFAR, A. et al. High potential of agro-industrial by-products of pomegranate (Punica granatum L.) as the powerful antifungal and antioxidant substances. Industrial Crops and Products, v.34, n.3, p.1523-1527, 2011. Disponível em: <http://www.sciencedirect.com/ science/article/pii/S0926669011001415>. Acesso em: 14 nov. 2013.

VUKSAN, V. et al. Using cereal to increase dietary fiber intake to the recommended level and the effect of fiber on bowel function in healthy persons consuming North American diets. American Journal of Clinical Nutrition, v.88, n.5, p.1256-1262, 2008. Disponível em: $<\mathrm{http}: / /$ ajcn.nutrition.org/content/88/5/1256.abstract $>$. Acesso em: 14 nov. 2013.

WACHIRASIRI, P. et al. The effects of banana peel preparations on the properties of banana peel dietary fibre concentrate. Songklanakarin Journal of Science and Technology, v.31, n.6, p.605-611, 2009.

YAPO, B.M.; KOFFI, K.L. Dietary fiber components in yellow passion fruit rind--a potential fiber source. Journal of Agricultural and Food Chemistry, v.56, n.14, p.5880- 
5883, 2008. Disponível em: <http://www.ncbi.nlm.nih.gov/ pubmed/18558700>.

ZERAIK, M.L. et al. Maracujá: um alimento funcional? Revista Brasileira de Farmacognosia, v.20, p.459-471, 2010.

ZERAIK, M.L. et al. Passion fruit: a functional food? Revista Brasileira De Farmacognosia-Brazilian Journal of Pharmacognosy, v.20, n.3, p.459-471, 2010.
ZERAIK, M.L. et al. Evaluation of the antioxidant activity of passion fruit (Passiflora edulis and Passiflora alata) extracts on stimulated neutrophils and myeloperoxidase activity assays. Food Chemistry, v.128, n.2, p.259-265, 2011.

ZERAIK, M.L. et al. Analysis of passion fruit rinds (Passiflora edulis): isoorientin quantification by HPTLC and evaluation of antioxidant (radical scavenging) capacity. Química Nova, v.35, p.541-545, 2012. 